\title{
Perda Auditiva Induzida por níveis de pressão sonora elevados em um Cirurgião-Dentista: Relato de caso
}

\author{
Hearing loss induced by high levels of sound pressure in a dentist: A case report
}

\author{
Karina Salvi ${ }^{* *}$ Ana Silvia Menezes Bastos ${ }^{*}$
}

Como citar esse artigo. Salvi, K; Bastos, ASM; Perda Auditiva Induzida por níveis de pressão sonora elevados em um CirurgiãoDentista: Relato de caso. Revista de Saúde. 2017 Jul./Dez.; 08 (2): 07-10.

\author{
Resumo \\ Trata-se de um relato de caso sobre perda auditiva em um dentista relacionada ao ambiente profissional e condições de \\ trabalho. \\ Palavras-chave: Ambiente de Trabalho; Audição; Equipamentos de Proteção Individual.
}

\begin{abstract}
This paper describes the case of a dentist with hearing loss due to work environment and conditions. Keywords: Work environment; Hearing; Personal protective equipment.
\end{abstract}

\section{Introdução}

A audição é fundamental à vida, e o órgão responsável por ela é o ouvido. O ouvido interno, principalmente a porção anterior, a cóclea, que é rica em líquidos de sódio e potássio e aloja o Órgão de Corti, é essencial para recepção da audição. O órgão é formado basicamente por células de sustentação e células secundárias ciliadas externas e internas (estereocílios).(1).

Em estado de excitação os estereocílios alongam e inclinam determinando assim, a abertura dos canais para as trocas de íons. A interrupção do funcionamento dos canais de íons pode levar à apoptose celular. $\mathrm{Na}$ exposição prolongada a níveis de pressão sonora acima de $85 \mathrm{~dB}$, as células perdem a motilidade e se soltam da membrana basilar, levando a uma exaustão metabólica, ou seja, ocorre uma intoxicação da célula, assim apoptose e consequentemente perda auditiva (1).

A perda auditiva induzida por níveis de pressão sonora elevados (PAINPSE) é o déficit auditivo provocado pela exposição por tempo prolongado a níveis de pressão sonora acima de níveis seguros e configura-se como uma perda do tipo neurossensorial, predominantemente coclear, geralmente bilateral, irreversível e progressiva, relativa ao tempo de exposição à determinada pressão sonora (2). Geralmente, não produz perda maior que $40 \mathrm{~dB}$ nas frequências baixas e $75 \mathrm{~dB}$ nas altas e sua progressão cessa com o fim da exposição. A existência da PAINPSE não torna o ouvido mais sensível a níveis elevados de pressão sonora. À medida que aumenta o limiar, a progressão da perda se dá de forma mais lenta, tendo seu início e predomínio nas frequências de 3,4 ou 6 $\mathrm{kHz}$, progredindo, posteriormente, para $8,2,1,0.5 \mathrm{e}$ $0.25 \mathrm{kHz}$. Considera-se que intervalos para repouso auditivo em ambientes adequados sejam fundamentais para tentar recuperar a atividade enzimática das células sensoriais (3).

O quadro clínico pode apresentar variações incluindo nervosismo, epigastralgia, estresse, hipoacusia, dificuldade de compreensão da fala, intolerância a sons intensos, diminuição de rendimento ao final do dia, desconforto, zumbido, plenitude auricular, diminuição da concentração, cefaleia, insônia, cansaço e variações de humor (4).

Ela é a doença ocupacional de maior incidência e a maior causa evitável de perda auditiva no mundo (5). Estudos epidemiológicos sobre perda auditiva no Brasil são escassos, portanto, não há registros que caracterizem a real situação. Estima-se que $25 \%$ da população trabalhadora exposta seja portadora de PAINPSE em algum grau (3).

Dentre os profissionais atingidos está o cirurgião-dentista, que traz ao longo de sua trajetória os problemas auditivos oriundos de níveis elevados de pressão sonora do ambiente clínico. Os altos níveis de ruído são advindos de várias fontes presentes no

Afiliação dos autores: † Discente do Curso de Medicina, Universidade Severino Sombra, Vassouras/RJ.

$\$$ Docente do Curso de Medicina, Universidade Severino Sombra, Vassouras/RJ.

* E-mail para correspondência: kaarina_salvi@hotmail.com 
consultório odontológico tais como, compressores de ar, sugadores de saliva, bombas de aspiração a vácuo e turbinas de alta rotação, além de outros fatores como som ambiente e ruído externo ao ambiente de trabalho (6). Em virtude disso, diferentes estudos têm analisado a relação entre os níveis de pressão sonora elevados no consultório odontológico, a carga horária do profissional, o tempo de atividade profissional e a perda auditiva nesses profissionais. O que se constata na maioria deles é que, mesmo expostos a níveis de intensidade sonora menores que $85 \mathrm{~dB}$, mas com tempo de exercício de profissão superior a cinco anos, apresentam perdas auditivas (5).

Dentre as formas de prevenção do desencadeamento ou agravamento da perda auditiva ocupacional, deve ser realizada uma avaliação audiológica anual, que pode ser realizada por uma bateria de exames incluindo a audiometria tonal por via aérea, audiometria tonal por via óssea, logoaudiometria e imitanciometria. Além desses exames, é necessário o uso de medidas de proteçãos como EPI (Equipamento de Proteção Individual) através de tampões auriculares (intra-canal) ou abafadores, cuja função é atenuar a potência da energia sonora transmitida ao aparelho auditivo (7).

A PAINPSE, por ser uma lesão de caráter irreversível, não possui nenhum tipo de tratamento clínico ou cirúrgico para recuperação dos limiares auditivos, sendo, portanto, necessário evitar sua instalação (8).

Diante disso, o presente trabalho tem como objetivo relatar um caso de PAINPSE em um cirurgiãodentista, cuja importância baseia-se na escassez de relatos médicos sobre esse tema na literatura.

\section{Relato de caso}

Um paciente masculino, 59 anos, branco, cirurgião-dentista, hipertenso controlado, que relata um episódio de acidente vascular cerebral (AVC) há 17 anos, mas que não deixou sequelas neurológicas, atualmente utilizando lisinopril (10mg), sinvastatina (20mg) e ácido acetilsalicílico associado (325mg), procurou o serviço de otorrinolaringologia com queixa de hipoacusia bilateral progressiva nos últimos cinco anos. Referiu dificuldade em manter diálogo com as pessoas, muitas vezes precisando que elas repitam a fala, pois não conseguiu escutá-las. Relatou reclamações de sua esposa pelo volume alto que assiste televisão e quando trabalha em seu consultório odontológico por um período maior que o de costume, percebe piora da acuidade auditiva. Trabalha há 32 anos na área da odontologia e negou fazer uso de tampões auriculares e história familiar de surdez e doenças congênitas na infância. Relatou apresentar respiração bucal, roncos e obstrução nasal, mas negou outros sintomas associados como otalgia, otorreia, zumbido e vertigem. Já foi submetido à cirurgia para correção de desvio de septo e posterior rinoplastia.

Ao exame de otoscopia foi observada ausência de eritema, estenoses, cerúmen, corpos estranhos, otorragia ou otorreia em condutos auditivos externos; membranas timpânicas íntegras, semitransparentes e de coloração cinza perolada, sendo possível a visualização do triângulo luminoso de Politzer, curta apófise, cabo do martelo e umbigo, bilateralmente.

Paciente foi orientado a realizar exames audiométricos, com finalidade diagnóstica, diferenciando o tipo de deficiência auditiva (condutiva ou neurossensorial) e o valor de perda que apresenta (Figura 1), os quais indicaram perda de caráter neurossensorial, bilateral e irreversível, sendo a profissão de cirurgiãodentista o provável causador desse quadro. O paciente foi orientado a reduzir, se possível, a carga horária de trabalho e realizar acompanhamento audiológico periódico, bem como a adotar medidas de prevenção.

\section{Discussão}

Diante do caso, a principal hipótese do diagnóstico etiológico seria PAINPSE, pelo fato do paciente ser cirurgião-dentista de longa data, e estar exposto a níveis elevados de pressão sonora no ambiente de trabalho. Estudos comprovam a interferência do ruído ocupacional na audição dos cirurgiões-dentistas com rebaixamento do limiar auditivo em forma de gota acústica na maioria dos profissionais, de acordo com tempo de atuação na odontologia, sendo o fator principal o tempo de atividade profissional (6).

Conforme o Comitê Nacional de Ruído e Conservação Auditiva, para ser considerada PAINPSE o nível elevado de pressão sonora de intensidade maior que $85 \mathrm{~dB}$ deve atuar sobre o ouvido suscetível durante oito horas diárias, ou dose equivalente, ao longo de vários anos (9). O paciente do caso exerce a profissão de cirurgião-dentista há 32 anos e consequentemente é exposto durante todo o período de trabalho.

Outro fator corroborativo para hipoacusia do paciente é a hipertensão arterial sistêmica, que associada à deficiência auditiva tem sido estudada em populações diagnosticadas com PAINPSE. Estudos já comprovam a associação da hipertensão arterial com deficiência auditiva $(10,11)$.

Quanto ao quadro clínico, os sintomas auditivos frequentes da hipótese diagnóstica de PAINPSE são hipoacusia, dificuldade de compreensão da fala, zumbido e intolerância a sons intensos. O trabalhador portador de PAINPSE também pode apresentar queixas como cefaleia, tontura, irritabilidade e problemas digestivos, entre outros (4). No relato, o paciente descreveu 
hipoacusia, dificuldade de compreensão de fala e piora da acuidade auditiva quando passa maior tempo no ambiente de trabalho, ou seja, confirma três dos sintomas frequentes do portador de PAINPSE, favorecendo este diagnóstico. Por outro lado, os zumbidos são o primeiro alerta de exposição a um estímulo sonoro excessivo (12) e o paciente do caso não relatava esta manifestação.

Em relação a equipamento de proteção individual (EPI), o cirurgião-dentista deve adotar a utilização de protetores auriculares quando utiliza canetas de alta e baixas rotações, sugador, peça reta, compressor, fotopolimerizador, autoclave, entre outros, para minimizar os riscos do desenvolvimento de PAINPSE (13). No caso descrito o paciente não fazia uso de EPI, o que certamente contribui para o desenvolvimento do problema.

A presbiacusia é o principal diagnóstico diferencial de PAINPSE. Denominada também como perda auditiva relacionada à idade, pode ser definida como uma perda neurossensorial progressiva, bilateral e simétrica devido à degeneração das estruturas do ouvido interno relacionada à idade. Pode ser considerada uma doença multifatorial complexa com fatores ambientais e genéticos, que afeta geralmente as altas frequências de audição. A maioria das pessoas atingidas está acima de 60 anos (14). . O cirurgião-dentista do caso pode apresentar componente de presbiacusia aliado ao diagnóstico de PAINPSE, devido à sua idade.

Sobre o diagnóstico da perda auditiva, é fundamental a realização da avaliação audiológica, sendo a audiometria o principal exame (7). Para que essa perda seja considerada PAINPSE ela deve ser sempre neurossensorial, ser quase sempre bilateral e, uma vez instalada, irreversível. Raramente provoca perdas profundas, não ultrapassando geralmente os 40 dBNA (decibels Nível Auditivo), ou dB(A), nas frequências baixas e 75 dBNA nas altas. A perda tem seu início, e predomina, nas frequências de 6.000, 4.000 e/ou $3.000 \mathrm{~Hz}$, progredindo lentamente às frequências de $8.000,2.000,1.000,500$ e $250 \mathrm{~Hz}$, para atingir seu nível máximo, nas frequências mais altas, nos primeiros dez a quinze anos de exposição estável a níveis elevados de pressão sonora (8).

O paciente relatado teve como resultado da audiometria tonal a perda auditiva neurossensorial nas frequências de 3000 a $8000 \mathrm{~Hz}$ bilateralmente, de grau leve a moderado à direita, e grau moderado à esquerda (Figura 1), confirmando o diagnóstico de PAINPSE..

Por ser uma perda auditiva irreversível, não há tratamento curativo. No entanto, existem tratamentos paliativos para melhorar a qualidade de vida do paciente, como utilização de próteses auditivas, além da prevenção para que não ocorra a progressão acentuada da perda auditiva, incluindo a diminuição da carga horária de trabalho, acompanhamento audiométrico e utilização assídua de EPI durante o trabalho.

\section{Conclusão}

O profissional da odontologia é realmente afetado pela PAINPSE e quanto mais tempo é exposto ao ruído, maior chance terá de apresentar perda auditiva, sendo essencial a prevenção da mesma.

\section{Referências}

1. Coelho MdSB, Ferraz JRdS, Almeida EdOC, Almeida Filho Nd. Otoacoustic emissions in the differential diagnosis of the noise-induced auditory losses. Revista CEFAC. 2010;12(6):1050-8.

2. Flores LS, Teixeira AR, Rosito LPS, Seimetz BM, Dall'Igna C. Pitch and loudness from tinnitus in individuals with noise-induced hearing loss. International archives of otorhinolaryngology. 2016;20(03):248-53.

3. Azevedo AN, Bernardo LD, Shing SCAC, Santos JN. Workers auditory profile at a meat warehouse. Revista CEFAC. 2010;12(2):223-34.

4. Ligocki C, Teixeira A, Parreira L, do Centro Universitário CdF, Hendrix MI. Efeito da Exposição a Elevados Níveis de Pressão Sonora sobre

\section{AUDIOMETRIA TONAL}

ORELHADIRETTA

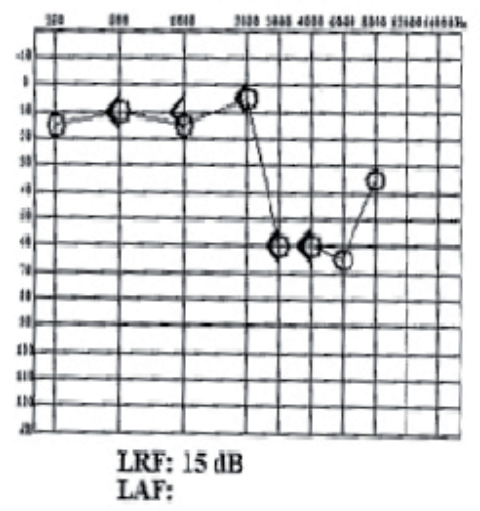

ORELHA ESQUERDA

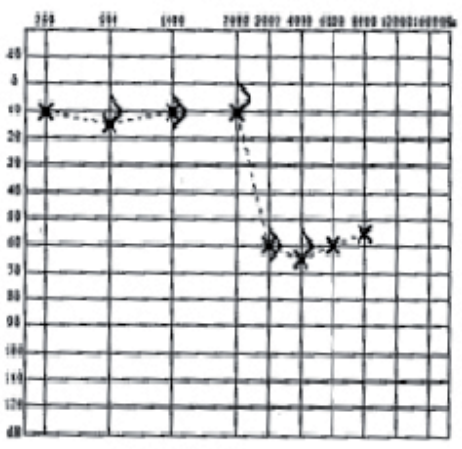

LRF: $15 \mathrm{~dB}$

LAF:

Figura 1. Audiometria tonal do paciente demonstrando perda auditiva bilateral nas frequências de 3000 a 8000 $\mathrm{Hz}$. 
o Organismo de Trabalhadores de Praça de Alimentação de Shopping Center. FONO-2008. Campos do Jordão-SP; 2008.

5. Lourenço EA, da Rocha Berto JM, Duarte SB, Greco JPM. Can noise in dental clinic produce hearing loss? Arquivos Internacionais de Otorrinolaringologia. 2011;15(01):084-8.

6. Nogueira SA, Bastos LF, Costa IdCC. Riscos ocupacionais em odontologia: revisão da literatura. Journal of Health Sciences. 2015;12(3).

7. Brasil PdI. com respeito à perda auditiva por ruído ocupacional. Diário Oficial. (131).

8. Farias N, Buchalla CM. A classificação internacional de funcionalidade, incapacidade e saúde da organização mundial da saúde\&58; conceitos, usos e perspectivas The international classification of functioning, disability and health $\& 58$; concepts, uses and perspectives. Revista brasileira de epidemiologia. 2005;8(2):187-93.

9. Seligman J. Comitê Nacional de Ruído e Conservaçäo Auditiva. Rev bras med otorrinolaringol. 1995;2(5):321-2.

10. Mondelli M, Lopes AC. Relação entre a hipertensão arterial e a deficiência auditiva. Arq Int Otorrinolaringol. 2009;13(1):63-8.

11. Talbott EO, Findlay RC, Kuller LH, Lenkner LA, Matthews KA, Day RD, et al. Noise-induced hearing loss: a possible marker for high blood pressure in older noise-exposed populations. Journal of occupational and environmental medicine. 1990;32(8):690-7.

12. Ogido R, da Costa EA, da Costa Machado H. Prevalência de sintomas auditivos e vestibulares em trabalhadores expostos a ruído ocupacional. Revista de Saúde Pública. 2009;43(2):377-80.

13. Santos MVA, de Godoy Camos FB, Campos JADB. Biossegurança na odontologia. Revista ReBraM. 2015;10(2):51-8.

14. Fischer N, Weber B, Riechelmann H. Presbycusis-age related hearing loss. Laryngo-rhino-otologie. 2016;95(7):497-510. 